\title{
The Rhetoric Structure of Research Article Abstracts in English Studies Journals
}

\section{Katalin Doró}

Writing clear and informative abstracts is a must for survival and promotion in any academic discourse community. Abstracts usually provide information about the background, the scopes and methodology of the research, the major findings and conclusions. Following Santos's (1996) model, forty research articles published in two English Studies journals were analyzed for the rhetoric moves they contain. Crossdisciplinary analyses revealed clear differences between the rhetoric structures of the twenty linguistics and twenty literature abstracts. It was found that the linguistics abstracts more often provided clear reference to the research scope, methodology and main results, while literature abstracts focused on the placement of the research into a wider context and offered a more tentative reference to the findings. Abstracts that contain less than three moves are often felt to be vague, especially for a reader who is an outsider to the close academic discourse community of the specific field of research. Differences were found between the abstracts published in the two journals, an explanation for which is difficult to find. An outcome of this research could be the sensibilization of expert researchers to the importance of writing clear abstracts, especially for journals that have wide readership, such as the large international community of scholars in English studies.

\section{Introduction}

Due to the increased number of academic publications and the need for the availability of one's research through online academic search engines, research article (RA) abstracts have gained importance in the past few decades. Today a limited number of articles appear without an abstract, and the abstracts provide a lens through which research becomes available to larger audiences. Therefore, writing clear, informative abstracts in English has become a crucial skill for scholars. It is through these abstracts that presentations are selected by conference organizers, papers are screened for review processes by journal editors, and potential readers decide to read and cite published articles. This 
is not a new phenomenon, but has been even more markedly highlighted by the electronic flow of academic discourse. As a result of their increasing importance in academic information exchange, RA abstracts have witnessed a growing interest from linguists starting from the 1980 os. Many studies have analyzed different sections or moves of RAs, including the introduction, methodology, results and conclusion (e.g., Hirano in the year 2009, and Sheldon in 2011). The concept of move in discourse analysis is a "discoursal or rhetorical unit that performs a coherent communicative function in a written or spoken discourse" (Swales, Research Genres 228-9). Santos, when explaining the choice of move as a unit of analysis of abstracts, states that "a move is to be considered as a genre stage which has a particular, minor communicative purpose to fulfill, which in turn serves the major communicative purpose of the genre" (485).

Most studies on the move structures of abstracts have focused on specific disciplines, such as medicine (e.g., Hartley in 2004), biology (e.g., Samraj in 2005) computer sciences (e.g., Lon et al. in 2012, and San et al. in 2012) or psychology (Martín-Martín in 2005). A number of studies have also been published on applied linguistics papers (e.g., Santos in 1996, Lorés in 2004, Pho in 2008, and Suntara and Usaha in 2013), but very few have considered literary texts. Stotesbury, in 2003 , for example, compared studies written in humanities with abstracts written in social sciences and natural sciences, but specific reference was not made to literary analyses. An attempt has also been made to find cross-linguistic and cross-disciplinary similarities in RA abstract structures published in different journals or written by students in different disciplines (e.g., Stotesbury in 2003, Samraj in 2005, Pho in 2008, and Zand-Vahili and Kashani in 2012).

Although several studies have addressed the rhetoric structures of RAs across disciplines and languages, to the best knowledge of this author, no research has addressed the move structures of RAs written in different fields of English Studies and published in the same journals. To fill this gap, this exploratory study addresses the question of how similar or different the rhetoric structures of RA abstracts published in European journals of English Studies are. Special attention is paid to the two markedly different fields in English studies, namely linguistics and literature. 


\section{Literature review}

\subsection{Abstract as a genre and its communicative purposes}

Abstracts can be considered as a distinct genre in academic writing. As Lorés (281) states, "there seems to be general agreement on three ways in which research abstracts differ from RAs. They differ in their function, in their rhetoric structures and in their linguistic realizations". John Malcolm Swales defines genre the following way:

A genre comprises a class of communicative events, the members of which share some set of communicative purposes. These purposes are recognised by the expert members of the parent discourse community, and thereby constitute the rationale for the genre. This rationale shapes the schematic structure of the discourse and influences and constrains choice of content and style. Communicative purpose is both a privileged criterion and one that operates to keep the scope of a genre as here conceived narrowly focused on comparable rhetorical action. In addition to purpose, exemplars of a genre exhibit various patterns of similarity in terms of structure, style, content and intended audience. If all high probability expectations are realised, the exemplar will be viewed as prototypical by the parent discourse community. (Genre Analysis 58)

Genre identification based on Swales's early definition, however, seems to be problematic as abstracts serve multiple communicative purposes and these purposes may not always be clear in different sections of the abstracts. These concerns have been noted by Swales himself in his later studies (e.g., Askehave and Swales in 2001). The authors promote a genre analysis based on both bottom-up (text based) and top-down (discourse community practices, values, beliefs based) identifications. They also note that genre functions and forms change with time and across discourse communities. When these ideas are interpreted in terms of RA abstracts, it can be concluded that RA abstracts, although clearly identifiable by their form and place in published works, may change considerably across disciplines and journals. Indeed, editors may ask for a specific length and content of the abstracts and may label these short texts in different ways. To illustrate, while abstracts can be considered brief summaries of the main elements of papers, journals might not ask for an abstract, but a summary, the function of which is to summarize findings without necessarily placing the paper into a wider context or introducing the 


\section{KATALIN DORÓ}

research questions and methods. However, most of the times these terms are used interchangeably. Regardless of the labeling, if salient information is not provided on the scope and the findings of the research, it is difficult to judge the originality and the added value of the published text.

Researchers have addressed different communicative purposes of RA abstracts. Some of the early studies argue for the informative function of abstracts. For example, Bhatia (82) refers to an abstract as a "faithful and accurate summary, which is representative of the whole article". Other studies have also highlighted this function of the RA abstracts to provide condense summaries of the articles (Santos in 1996, Lon et al. in 2012). Based on the idea that the abstract is the abbreviated form of the paper, Bhatia proposed a rhetoric structure which indicates the four main sections of a research paper: introduction, methods, results and conclusion. Moreover, some scholars have called attention to the persuasive rather than a simple descriptive function of abstracts. As Hyland (in 2000) argues, abstracts need to persuade the reader to read on and take a look at the entire paper. Readers must be selective in what they access and digest, as the information flow of newly published research is too massive to be read. We can also add here that if readers are not convinced of the usefulness of articles, they will not further search for, purchase, read and cite them. As a result, even excellent research papers may stay unnoticed if their abstracts are not informative and convincing enough.

In order to persuade their readers, experienced authors make adequate structural and linguistic choices while constructing their abstracts. Good RA abstracts use a special metadiscourse to orient the reader in the interpretation of the information. These, for instance, include transition words and frame markers (in addition, to conclude), hedges (perhaps, possible), boosters (definitely, it is clear), attitude markers (surprisingly, agree), self-mentions (I, we, our) and engagement markers (you can see, one might consider). As Hyland (2005: 9-12) states, the efficient use of metadiscourse promotes coherence, and also makes texts reader-friendly by guiding and involving the reader. Other lexical choices, such as noun and verb phrases, also indicate the authors' intention to promote their research. In Disciplinary Discourses: Social Interaction in Academic Writing, Hyland argues that, alongside specific rhetorical features such as markers, rhetoric moves also serve to inform, and in more successful cases, persuade the reader. In this comprehensive study, published in 2000, he analyzed 800 abstracts across various disciplines to see whether they contained all five identified moves (introduction, purpose, method, product and conclusion). He found some variation across and within disciplines and concluded that 
especially the first and the last moves indicate the writers' attempt to place their research within the already existing mass of academic findings and to evaluate and promote their own research, yet they are less frequently used than the mid three moves.

Based on their communicative purpose, information content and structure, two main types of abstracts can be distinguished, namely indicative and informative (Martín-Martín 6). Indicative abstracts, also called descriptive, give a general overview of the topics covered in the article (Youdeowei et al. 30). It is easier to write this first type of abstract as they only provide a short description of the research background or the topics mentioned in the paper. They are more appropriate for longer pieces of work such as books or review articles than research papers. As Youdeowei, Stapleton and Obubo claim, indicative abstracts are "the lazy way of writing an abstract; many journals will ask for a more informative version" (30). Since descriptive abstracts of research articles do not provide enough information about the true nature of the papers, these abstracts often remain vague, may not be convincing enough and may even lose readership. More specific information is provided for prospective readers in informative abstracts, in which reference is made to the research context and methodology, main results and conclusions. Since more detail is provided, readers can better assess the paper in terms of its relevance, novelty and usefulness. Although abstracts are usually preceded by the title, they are often separated from the RA; still they have to be able to stand on their own. Abstracts that do not fulfill this requirement are not serving their readers well.

\subsection{Research on the rhetoric structures of research articles}

Interest in the rhetoric organization of research article sections has been growing for many decades among researchers, and pioneering studies have been carried out starting from the 1980 . Swales, back in 1981, constructed a fourmove model of introductions, which included the following: establishing the research field, reporting previous research, preparing and finally introducing the present research. Later he revisited the model and this revised version contains three distinct moves. This Create a Research Space (CARS) model consists of the following main moves: establishing the territory, establishing the niche and occupying the niche (Swales, Genre Analysis). A few years later he concluded that this model had become prototypical in the introductions of many journals (Swales, Research Genres). Swales also established various steps within his moves. For example, creating the niche may be done by 


\section{KATALIN DORÓ}

pointing out gaps in previous research, raising questions, or continuing certain research traditions. The CARS model has been used by a number of studies to investigate the rhetoric structure of RA introductions (e.g., Samraj in 2005, Ozturk in 2007, Hirano in 2009, and Sheldon in 2011).

While the introduction is usually the first full section of a research paper that we encounter, abstracts have taken a major role in informing readers about the scope and content of the paper. After the initial research by Swales on the introduction sections, more attention has been paid to the analysis of RA abstracts. Santos, in 1996, constructed a five-move model, including the following moves: situating the research, presenting the research, describing methodology, summarizing the findings and discussing the findings. In order to help the identification of each move based on both semantic and linguistic information, Santos assigned functions to each move in the form of questions that they should answer (see Table 1) (Santos). This model has been used to identify the move structure of both published RAs and theses written by student writers (e.g., Pho in 2008, Tseng in 2011, Lon et al. in 2012, and Doró in 2013). Santos, Pho and Tseng all identified obligatory and non-obligatory moves in applied linguistics abstracts and concluded that moves 2, 3 and 4 are obligatory. These findings are very similar to the conclusions drawn by Doró in 2013 who compared abstracts of undergraduate EFL English theses and found that the applied linguistics abstract followed the model closer than the abstract written on literature, culture and history topics. A move was considered obligatory by Santos if it appeared in at least $80 \%$ of articles. Doró (185) found that while move 2 (presenting the research) occurred in all the theses, move 3 (methodology) showed a 92 and $90 \%$ result and move 4 (findings) a 92 and $42 \%$ occurrence for the linguistics and the non-linguistic theses, respectively. These findings indicate that the results were not summarized in more than half of the literature, culture and history theses. Lon and colleagues (64) also found move 4 to be non-obligatory in computer and communication system engineering journals. 
Table 1: Framework for a five-move structure analysis of RA abstracts (based on Santos)

\begin{tabular}{lll}
\hline Moves & Functions & Questions to ask \\
\hline $\begin{array}{l}\text { 1. Situating } \\
\text { the research }\end{array}$ & $\begin{array}{l}\text { Setting the scene, topic } \\
\text { generalization }\end{array}$ & $\begin{array}{l}\text { What has been known about } \\
\text { the field/topic of research? }\end{array}$ \\
$\begin{array}{l}\text { 2. Presenting } \\
\text { the research }\end{array}$ & $\begin{array}{l}\text { Setting the purpose of the } \\
\text { study, research questions/ } \\
\text { hypotheses }\end{array}$ & What is the study about? \\
$\begin{array}{l}\text { 3. Describing } \\
\text { the methodology }\end{array}$ & $\begin{array}{l}\text { Describing the materials, } \\
\text { subjects, variables, procedures }\end{array}$ & How was the research done? \\
$\begin{array}{l}\text { 4. Summarizing } \\
\text { the findings }\end{array}$ & $\begin{array}{l}\text { Reporting the main findings } \\
\text { of the research }\end{array}$ & What did the research find? \\
$\begin{array}{l}\text { 5. Discussing } \\
\text { the findings }\end{array}$ & $\begin{array}{l}\text { Interpreting the results, } \\
\text { giving recommendations, } \\
\text { implications, applications }\end{array}$ & $\begin{array}{l}\text { What do the results mean? } \\
\text { So what? }\end{array}$ \\
\hline
\end{tabular}

A four-move structure has also been used by researchers, referred to as the IMRD or IMRaD framework (e.g., Swales in 1990, Bhatia in 1993, and Lorés in 2004). These acronyms refer to the Introduction, Methods, Results, Discussion sections of abstracts. This is a framework very similar to that of Santos with the only difference being that the first two moves in the Santos model are combined here. Indeed, the Introduction move in the IMRD model should provide information about the context of the research, the author's interests, the aims of the study and the research questions. Lorés analyzed abstracts published in applied linguistics journals and compared the thematic distribution of moves according to both the IMRD and the CARS models. She found that $61 \%$ of the abstracts followed the IMRD model, $30.5 \%$ the CARS structure and $8 \%$ a combination of the two.

The five or four-move structures seem to address the same purpose of informing the readers about the main pieces of information in the article, although key moves are often missing from abstracts. The need for a more standardized abstract writing has been fulfilled by the use of structured abstracts in journals and conference application procedures in certain 
disciplines, such as medical sciences and psychology. As James Hartley points out, "structured abstracts represent an improvement over traditional abstracts because not only is there more information presented but also their format requires their authors to organize and present their information in a systematic way - one which aids rapid search and information retrieval when looking through abstract databases" ("Improving the Clarity" 366). Structured abstracts usually provide the following subheadings: background, aim, method, results and conclusions. Hartley argues that although structured abstracts occupy more space in print, this is not such a problem for online versions. He states that "with the extra lines comes extra information. It may be that more informative abstracts might encourage wider readership, greater citation rates and higher journal impact factors - all of which authors and editors might think desirable" ("Improving the Clarity" 370). In 2004, Hartley reviews research on structured abstracts and concludes that, although not all advantages are straightforward and not all authors and editors prefer this more rigid format, structured abstracts are better than traditional ones as they force authors to systematically think over and present their research ("Current Findings").

\section{Methodology}

The corpus of the forty RA abstracts chosen for this study comes from two English studies journals issued between 2009 and 2011. Selection criteria included the peer-reviewing of submitted manuscripts, the publishing of more than one annual issue and the inclusion of linguistics papers in all three years. Although a number of European journals have English Studies indicated in their titles, and have as their aim the publishing of studies on literature, linguistics and culture, many have a predominance of literature articles or do not publish linguistics papers. Some examples include the Hungarian fournal of English and American Studies and the European Fournal of English Studies that do not include articles on linguistics.

The two journals selected for this study, namely English Studies (ES) and the Nordic Fournal of English Studies (NJES) are slightly different in their profile, which was a deliberate choice to see whether publishers and aims change the structure of the abstracts. English Studies, published by Francis and Taylor, has a nearly-hundred-year history and nowadays issues up to eight volumes per year, some of which are special issues, but none of these are on linguistics. 
Five or six research articles appear in each issue. Of these, only one or rarely two studies are language-related, including theoretical, historical and applied linguistics. The Nordic Journal of English Studies has been published since 2002 by the Nordic Association of English Studies, and has been issued one to three times a year. If multiple issues are published a year, at least one of them is dedicated to applied linguistics studies. It can be concluded, therefore, that while the first journal reflects the traditional, literature-dominated views of English Studies, the second journal is more balanced in terms of the disciplines it provides space for.

Ten linguistics and ten literature abstracts were extracted from both of the journals. The abstracts were of similar sizes to ensure comparability. This exploratory study works with the five-move pattern described by Santos and used in a variety of other studies (see Table 1 above). This framework offers more detail than the three- or four-move models and is considered to be a better indicator of similarities and differences in RA abstracts across disciplines and journals. Contrary to previous research which compared abstracts published in different journals, for this study RAs that appeared in the same English Studies journals were selected. Since the readership of English Studies journals is thought to be wider and more heterogeneous than readers of specific literature and linguistics journals, it is hypothesized that these abstracts show a close similarity across the two disciplines and follow a logical move structure sequence to better inform scholars who are not experts in the given topics.

Although rhetoric structure models are widely used internationally, Elena Sheldon, together with other researchers, addressed the problematic nature of identifying moves as subjectivity plays a role in the decision making process. This is especially true in the case of authors who do not provide sufficient linguistic clues to mark the boundaries between their moves. In order to balance this subjectivity, double rating was done by the author of this study at two widely separate times, with a three-month interval between the two ratings. The two manual ratings were compared and in cases where there were a few minor discrepancies, the final decision was made on the basis of the information content and the linguistic realization of the moves. Phrases, connectives and certain clauses (such as I would argue, this paper is concerned with, the article discusses, this paper investigates, the essay explored various ideas, the results showed, other conclusions of this research, however critics have been ambiguous on the topic...) in most cases clearly marked the boundaries between moves, although it is beyond the scope of this article to show in detail the linguistic 


\section{KATALIN DORÓ}

realization of the moves. Abstracts were rated without looking at the titles or the various sections of the articles, since it was believed, as stated also by other researchers, that abstracts need to be able to stand on their own. The same criteria have been applied by previous research (e.g., Santos, Pho, Hirano, and Doró). As an initial step, each sentence was assigned to a move (for examples refer to Tables 4 and 5), but as moves can be signaled by clauses or single words, often the same sentence was marked as two different moves. To illustrate, it is often the case in abstracts that moves 2 and 3 are placed within the same sentence (e.g., Drawing on the results of a series of online questionnaires, the paper ascertains how the project was evaluated...; In order to bridge this gap, the present paper offers a corpus-based analysis of ...; This article examines a number of such texts by linking the notion of punctuality to the general nineteenth-century wish for self-improvement and social progress). If insufficient information was given in the abstracts to orient the reader, for example, whether statements referred to previous studies (move 1) or to the findings of the given study (move 4), the second rating was taken into consideration that was done after working with the actual corpus for several months. In cases where the entire abstract was following a single line and even the title did not help in deciding whether the information referred to background knowledge or the outcome of the research (without reading the article itself), the abstract was double marked as move $1 / 4$ (see the example in the Endnotes).

Abstracts that appeared in the journal English Studies are referred to as ESling and ESlit, followed by a number (1-10) in each group. Similarly, abstracts from the Nordic fournal of English Studies are marked as NJESling and NJESlit.

\section{Results and discussion}

Findings from the analysis using Santos's model are shown in Table 2 for the English Studies journal. Number 1 is indicated if the specific move is present in any part of the abstract and o if it is absent or unidentifiable. Double occurrences of the same moves within the abstracts are disregarded at this initial stage of the analysis. Results reveal similar general tendencies in the two disciplines. For both groups of abstracts, move 2 (presenting the research) is the most frequent one with $100 \%$ and $90 \%$, followed by a $90 \%$ occurrence of moves 3 and 4 (methodology and findings), and an $80 \%$ occurrence of move 1 (situating the research) in the linguistics abstracts. Similarly, moves 1 and 3 
appear in $80 \%$ of the literature abstracts, while move 4 occurs in $70 \%$ of the cases. Move 5 is the least often applied move, with a $40 \%$ occurrence rate in the linguistics and only $20 \%$ in the literature abstracts.

Most figures are lower than the ones found by previous research. For example, Pho reported a $50 \%$ to $70 \%$ of occurrence for move 5 in computer technology and applied linguistics. On the contrary, San and Tan found only a $20 \%$ occurrence rate for the same move in their corpus of computer and communication system engineering papers. This suggests that move 5 is nonobligatory and its appearance in RAs varies greatly. While previous research has reported on the non-obligatory nature of move 1 (situating the research), both disciplines indicate a high, $80 \%$ occurrence in our corpus. This means that most authors found it important to refer to previous research, define terminology or introduce the literary work under investigation.

Table 2. Move structure of abstracts published in English Studies

\begin{tabular}{|c|c|c|c|c|c|c|c|c|c|c|c|}
\hline \multicolumn{6}{|c|}{ English Studies linguistics abstracts } & \multicolumn{6}{|c|}{ English Studies literature abstracts } \\
\hline & $\mathrm{Ml}$ & $\mathrm{M}_{2}$ & $\mathrm{M}_{3}$ & $\mathrm{M}_{4}$ & $\mathrm{M}_{5}$ & & Mi & $\mathrm{M}_{2}$ & $\mathrm{M}_{3}$ & $\mathrm{M}_{4}$ & $\mathbf{M}_{5}$ \\
\hline ESling1 & 1 & 1 & 1 & 1 & $\mathrm{o}$ & ESlitı & 1 & 1 & 1 & 1 & $\mathrm{o}$ \\
\hline ESling 2 & 1 & 1 & 1 & 1 & 1 & ESlit2 & 1 & 1 & 1 & 1 & 1 \\
\hline ESling3 & 1 & 1 & 1 & o & o & ESlit3 & 1 & 1 & 1 & o & $\mathrm{o}$ \\
\hline ESling4 & 1 & 1 & 1 & 1 & $\mathrm{o}$ & ESlit4 & $\mathrm{o}$ & $\mathrm{o}$ & $\mathrm{o}$ & 1 & $\mathrm{o}$ \\
\hline ESling 5 & 1 & 1 & 1 & 1 & o & ESlit5 & 1 & 1 & 1 & 1 & 1 \\
\hline ESling6 & $\mathrm{o}$ & 1 & 1 & 1 & 1 & ESlit6 & 1 & 1 & 1 & o & o \\
\hline ESling7 & o & 1 & $\mathrm{o}$ & 1 & 1 & ESlit7 & 1 & 1 & $\mathrm{o}$ & 1 & $\mathrm{o}$ \\
\hline ESling8 & 1 & 1 & 1 & 1 & o & ESlit8 & o & 1 & 1 & 1 & o \\
\hline ESling9 & 1 & 1 & 1 & 1 & o & ESlit9 & 1 & 1 & 1 & o & o \\
\hline ESlingıo & 1 & 1 & 1 & 1 & 1 & ESlitıo & 1 & 1 & 1 & 1 & $\mathrm{O}$ \\
\hline ES ling & 8 & 10 & 9 & 9 & 4 & ES lit & 8 & 9 & 8 & 7 & 2 \\
\hline
\end{tabular}

Results for the Nordic Fournal of English Studies corpus are reviewed in Table 3 below. For this set of abstracts more differences than similarities are found in the move structures of the linguistics and the literature RAs, both in terms of distribution and proportion. For the linguistics papers moves 2 and 3 are obligatory and appear in all ten abstracts, followed by move 4 with 6o\%, 


\section{KATALIN DORÓ}

move 1 with $50 \%$ and move 5 with $30 \%$ of occurrences. These figures closely reflect Santos's original findings, although the results are discussed in only six of the ten abstracts, which is below the usual occurrence rate in applied linguistics RA abstracts. Hyland (2004) found an increasing trend of using move 1 in applied linguistics abstracts; however, the results of this study do not support this with the $50 \%$ rate. This may be due to the fact that the ten abstracts represent various sub-fields of linguistics.

Abstracts that do not provide clear information about the findings in move 4 may invite readers to read the paper by creating an information gap, but could also risk being abandoned by potential readers due to a certain lack of conciseness. Readers might choose other articles that clearly indicate the outcome of the research already in the abstract. As was discussed in the literature review section of this study, quick, most often online browsing through abstracts is a first step in selecting articles from the massive flow of academic information that is available for researchers and scholars (see Hyland, Disciplinary Discourses).

The most unusual pattern of moves was found in the NJES literature corpus. As shown in Table 3 , in three cases it was difficult to decide whether certain statements are intended to be results, background information, aims or methods. These cases are indicated with half points. This is unusual and deceives the purpose of an abstract that should provide a clear lens through which readers gain access to the project and its outcome. Surprisingly, the introductory move was the most often employed one (75\%), followed by move $3(70 \%)$, move $2(60 \%)$, move $4(45 \%)$ and finally move $5(10 \%)$. This pattern indicates that some of the authors used the strategy of a vague introduction of the discussed topics rather than explicitly arguing for the importance of their research. This results in indicative rather than informative abstracts, a strategy which was argued against in the reviewed literature for RAs (see Hyland, Disciplinary Discourses and Metadiscourse; Hartely "Improving the Clarity" and "Current Findings"; Youdeowei et al.). 
Table 3. Move structure of abstracts published in the Nordic Fournal of English Studies

\begin{tabular}{|c|c|c|c|c|c|c|c|c|c|c|c|}
\hline \multicolumn{6}{|c|}{$\begin{array}{r}\text { Nordic fournal of English Studies } \\
\text { linguistics abstracts }\end{array}$} & \multicolumn{6}{|c|}{$\begin{array}{r}\text { Nordic Fournal of English Studies } \\
\text { literature abstracts }\end{array}$} \\
\hline & Mi & $\mathrm{M}_{2}$ & $\mathrm{M}_{3}$ & $\mathrm{M}_{4}$ & $\mathrm{M}_{5}$ & & Mi & $\mathrm{M}_{2}$ & $\mathrm{M}_{3}$ & $\mathrm{M}_{4}$ & $\mathbf{M}_{5}$ \\
\hline NJESling1 & $\mathrm{O}$ & 1 & 1 & 1 & $\mathrm{O}$ & NJESlitı & $\mathrm{O}$ & $\mathrm{o}$ & $\mathrm{O}$ & 1 & 1 \\
\hline NJESling2 & 1 & 1 & 1 & $\mathrm{O}$ & $\mathrm{O}$ & NJESlit2 & 1 & 1 & 1 & 1 & $\mathrm{O}$ \\
\hline NJESling3 & o & 1 & 1 & 1 & 1 & NJESlit3 & $\mathrm{o}$ & 1 & 1 & $\mathrm{O}$ & o \\
\hline NJESling4 & o & 1 & 1 & o & $\mathrm{o}$ & NJESlit4 & 1 & 1 & 1 & 0.5 & $\mathrm{O}$ \\
\hline NJESling5 & o & 1 & 1 & 1 & $\mathrm{o}$ & NJESlit5 & 1 & $\mathrm{o}$ & 1 & 1 & $\mathrm{o}$ \\
\hline NJESling6 & o & 1 & 1 & o & $\mathrm{O}$ & NJESlit6 & 1 & 1 & $\mathrm{o}$ & $\mathrm{O}$ & $\mathrm{O}$ \\
\hline NJESling7 & 1 & 1 & 1 & 1 & 1 & NJESlit7 & 0.5 & o & $\mathrm{o}$ & 0.5 & $\mathrm{O}$ \\
\hline NJESling8 & 1 & 1 & 1 & o & $\mathrm{o}$ & NJESlit8 & 1 & o & 1 & 0.5 & $\mathrm{O}$ \\
\hline NJESling9 & 1 & 1 & 1 & 1 & 1 & NJESlit9 & 1 & 1 & 1 & $\mathrm{O}$ & $\mathrm{O}$ \\
\hline NJESling10 & 1 & 1 & 1 & 1 & $\mathrm{o}$ & NJESlitıo & 1 & 1 & 1 & 0 & o \\
\hline NJES ling & 5 & 10 & 10 & 6 & 3 & NJES lit & $7 \cdot 5$ & 6 & 7 & $4 \cdot 5$ & $\mathbf{1}$ \\
\hline
\end{tabular}

It is possible only to hypothesize what brings the differences found across the two journals and the two disciplines. The limited data set restricts the generalizability of the conclusions to be drawn, but is sufficient to show tendencies. Reasons for the differences between the two journals could be the higher selection rates for the journal English Studies and the publishing of articles from different English Studies disciplines within the same volumes. These aspects probably push authors to be as specific and reader-friendly as possible already in their abstracts. It is also worth noting that linguists and literary scholars form distinct communities of practice (see Lave and Wenger; and Wenger) within which, due to information sharing, socialization and relatively narrow area of purposes and expertise, they understand each other's research even based on limited information. However, they need to avoid the marginalization of non-expert readers and consider outside of the community scholars especially when they publish in mixed-discipline journals.

The group of abstracts that stand out the most is the NJES literature RAs. These, as a group, operate with the lowest number of moves, although some of them received double marking. NJESlit7, for example, provides no 


\section{KATALIN DORÓ}

linguistic clue to be able to decide whether the sentence flow refers to previous research or is the summary of the thinking process indicated in the article. Three of the abstracts in this group also give reference to only two moves. However, two linguistics abstracts use the same strategy in this journal, so we cannot clearly state that two-move abstracts either in literature or linguistics cannot be published. It is the subject of further study to analyze more closely the linguistic realization of the moves that occur in each article and to see how traditions of publishing and abstract writing in the two fields differ. It would also be useful to test the degree of clarity of these abstracts seen by groups of scholars, the readers themselves, from and outside the given fields and communities of practice in order to see how efficient those abstracts are which operate with a limited number of moves. Table 4 shows an example of a linguistics abstract that contains all five moves and clearly marks the various moves by introductory lexical units. These underlined strings of words help the identification of the moves and the understanding of the text. This abstract also demonstrates that moves often do not follow each other in order, but can change places or even reoccur later.

Table 4. Analysis of the move structures in a linguistics abstract (Simon, Ellen and Miriam Taverniers. "Advanced EFL learners' beliefs about language learning and teaching: a comparison between grammar, pronunciation, and vocabulary." English Studies 92.8, (2011): 896-922.)

\begin{tabular}{ll}
\hline Moves & Sentences \\
$\begin{array}{l}\text { M2. Presenting } \\
\text { the research } \\
\text { S1 }\end{array}$ & $\begin{array}{l}\text { This paper reports on the results of a study exploring learners' } \\
\text { beliefs on the learning and teaching of English grammar, } \\
\text { pronunciation, and vocabulary at the tertiary level. }\end{array}$ \\
\hline $\begin{array}{l}\text { M1. Situating } \\
\text { the research }\end{array}$ & $\begin{array}{l}\text { While the importance of learners' beliefs on the acquisition } \\
\text { process is generally recognized, few studies have focused on } \\
\text { and compared learners' views on different components of the } \\
\text { language system. }\end{array}$ \\
\hline $\begin{array}{l}\text { M3. Describing } \\
\text { the methodology } \\
\text { S3 }\end{array}$ & $\begin{array}{l}\text { A questionnaire containing semantic scale and Likert scale } \\
\text { items probing learners' views on grammar, pronunciation, and }\end{array}$ \\
\end{tabular}


M4. Summarizing the findings $\mathrm{S}_{4}$

The analysis of the responses revealed that (i) vocabulary was considered to be different from grammar and pronunciation, both in the extent to which an incorrect use could lead to communication breakdown and with respect to the learners' language learning strategies, (ii) learners believed in the feasibility of achieving a native-like proficiency in all three components, and (iii) in-class grammar, pronunciation and vocabulary exercises were considered to be useful, even at the tertiary level.

M5. Discussing the findings $\mathrm{S}_{5}$
The results are discussed in light of pedagogical approaches to language teaching.

$\mathrm{M}=$ move, $\mathrm{S}=$ sentence

Sample 2 in Table 5 indicates an abstract that employs only three, rather clear moves, although it could be argued that the first sentences marked as move 1 are not all referring to previous knowledge on the manuscripts. This becomes clearer only if one reads the article or has more knowledge on the given topic. It is a frequently reoccurring problem, especially in the reviewed literature abstracts, that the authors provide no or limited reference to themselves (we, I would argue, my examination) or the article (this article discusses, the essay explores, an analysis of $X$ shows), and therefore the aim of statements and the added value of the sentences in the abstracts remain unclear or uncertain. On the contrary, in sample 2 the underlined phrases (we analyse; in order to come to a better understanding) greatly help in the identification of the moves and the differentiation between the background information and the aims of the research presented.

Altogether, the literature abstracts seem to employ markedly less linguistically explicit references to the various moves than the linguistics abstracts, and markers are also more tentative. For example, the verbs argue, claim, examine and show in literature abstracts are used interchangeably to refer both to the research aims and the outcome of the research. Linguistics papers, especially the ones that report on empirical investigation, mark their move boundaries more efficiently. Linguistics abstracts, however, which do not report on empirical data collection and analysis, also tend to employ fewer moves or to mark move boundaries less clearly. 
Table 5. Sample 2: Analysis of the move structures in a literature abstract (Chardonnens, László Sándor and Rosanne Hebing. "A Descriptive Analysis of Nijmegen, Universiteitsbibliotheek, HS 194, a Late Medieval English Manuscript at Nijmegen University Library." English Studies 92.1 (2011): 20-38.)

\begin{tabular}{ll}
\hline Moves & Sentences \\
\hline & HS 194, a late medieval manuscript in the collection of Nijmegen \\
University Library, is relatively unknown to scholars of Middle \\
English. The manuscript, a small and rather soberly decorated \\
prayer book, contains a range of devotional material in English and \\
in Latin, in some cases uniquely attested and hitherto unknown. \\
An added attraction to Nijmegen 194 is the detailed record of \\
post-medieval ownership notes, entered into the manuscript by \\
several generations of a single family of owners. These family \\
records enable the present-day user to trace the whereabouts of \\
the manuscript from the mid-sixteenth century until the end of the \\
S1-7 \\
nineteenth century. The manuscript is a composite whose contents \\
are divided across eleven booklets. Analysis of the manuscript's \\
layout, script and decoration, as well as indications from the book's \\
contents, point towards a fifteenth-century English origin. The \\
majority of booklets that make up Nijmegen 194 do not seem to \\
be designed to accompany each other; the manuscript as a whole \\
probably came into existence in the hands of the first identifiable \\
sixteenth-century owners.
\end{tabular}

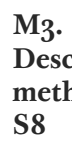

M2. Presenting the research S8
HS 194, a late medieval manuscript in the collection of Nijmegen prayer book, contains a range of devotional material in English and in Latin, in some cases uniquely attested and hitherto unknown. An added attraction to Nijmegen 194 is the detailed record of post-medieval ownership notes, entered into the manuscript by reverds enable the present-day user to trace the whereabouts of the manuscript from the mid-sixteenth century until the end of the nineteenth century. The manuscript is a composite whose contents are divided across eleven booklets. Analysis of the manuscript's layout, script and decoration, as well as indications from the book's contents, point towards a fifteenth-century English origin. The majority of booklets that make up Nijmegen 194 do not seem to be designed to accompany each other; the manuscript as a whole sixteenth-century owners.

\section{$\mathrm{M}=$ move, $\mathrm{S}=$ sentence}

The cycle patterns of moves both in abstracts and introductions have been noted by previous research (e.g., Sheldon, or Doró). Move cycles that are different from the traditional numbering are seen both in linguistics and literature abstracts. Some moves occur more than once or change places compared to the suggested order. Move patterns such as 1-3-2-3, 1-2-4-3-4, $2-1-2-3,1-2,2-3$ are also found in this corpus. There are only five abstracts in 
the corpus that indicate all five moves, and four of these follow the linear order from 1 to 5 . The remaining one is illustrated in Table 4, with the first two moves changing places, and in this way highlighting the aim of the new study before putting it into the context of previous research.

\section{Conclusion}

This study examined forty RA abstracts published recently in two English Studies journals. The analysis of the rhetoric structure of the abstracts showed that only a few of them follow the full structure suggested by Santos. Only five abstracts included all five moves. Although there was a variation in the pattern, the most frequently employed moves were move 2 (presenting the research) and move 3 (methodology), although not all the abstracts provided information about these two moves. Reference to move 4 (findings) showed considerable variation across the four sub-corpora. Moreover, move 1 (situating the research) and move 5 (discussion of findings), found as non-obligatory moves by earlier research, also significantly varied across the sub-corpora, with move 5 remaining the least preferred and least commonly used section of the abstracts. The analysis suggests that three moves in an abstract provide a good guideline to the reader in terms of what can be expected from the paper itself, but fewer moves may leave the reader with insufficient information.

With regard to the similarities and differences between linguistics and literature abstracts, the first group seemed to follow the five-move structure more closely and fully, although individual variations were seen in terms of the move cycles and the length of each move. Abstracts with only two moves were found more often among the literature abstracts in both of the journals, and the application of only one move within the same abstract was also detected only in two literature abstracts.

As for the differences in the rhetoric structures of abstracts published in the two journals, the two linguistics sub-corpora showed more resemblance than the two literature ones. This indicates that it is difficult to draw a final conclusion with regard to the move structure of abstracts even within the same discipline and studies published in similar journals, but it is an easier task in the case of linguistics. Many factors may play a role in the final structure and content of abstracts, including field- or journal-specific academic writing traditions, reviewer or editor preferences, or the readership of the journals. However, this study argues that regardless of these variations, abstracts need 


\section{KATALIN DORÓ}

to be clear, concise, accurate and understandable for readers. Journals that publish papers from different fields of studies must follow these rules of thumb even more closely in order to satisfy the needs of wide readerships, such as in the case of English Studies journals.

Using both qualitative and quantitative analyses, this study strives to extend our knowledge of research that has used the Santos (1996) model and other similar models of rhetoric structures. This study has also some practical and pedagogical implications. Researchers who prepare their papers must pay close attention to the abstract they submit as much as to the rest of their paper. Inexperienced writers should study carefully abstracts written not only in their close circle of research community, but also in other fields in order to gain a critical point of view regarding academic writing and to develop an efficient writing process. Another outcome of this research could be the sensibilization of expert researchers to the importance of writing clear abstracts in order to promote their research and gain readership, especially if they publish in journals that serve large international communities of scholars.

Although this study highlighted some tendencies in the rhetoric structures of English Studies RA abstracts, it is not without limitations. A closer investigation is needed into the linguistic realization of the moves to better understand the differences found between linguistics and literature abstracts. As abstract clarity is subjective to a certain extent, testing the clarity of selected move structures among readers might also shed light on new aspects. Future research could also focus on journals other than the two used in the present study (ES and NJES) to see how universal the differences and the similarities are between the two investigated disciplines.

\section{Notes}

Abstract with a single move, rated as move 1/4. Löfrgen, Hans. "Cooper's Pioneer: Breaking the chain of representation." Nordic Fournal of English Studies 8.3 (2009): 1-19.

In Cooper's Pioneers, the transition from "national literature" and a realist epistemology of representation toward a Romantic imaginary and increasingly individualized politics is linked to the decline of liberal political philosophy and to the loss of landed property as the political basis of society. While the dominant narrative reconciles two families, healing the breach between colonial and postrevolutionary society, displacing Indian claims, and relegitimizing land ownership, a tragic epilogue - the regressive departure of the pioneer toward a new frontier - opens 
up a Romantic subnarrative of desire. A complementary psychosexual narrative and discourse relocates the origin, so deliberately theorized in this novel in terms of natural property rights, in oedipal problematics. It is a regressive move which, paradoxically, also constructs the post-Enlightenment subject.

\section{Works Cited}

Askehave, Inger and John Malcolm Swales. "Genre Identification and

Communicative Purpose: A Problem and a Possible Solution." Applied Linguistics 23.2 (2011): 195-212.

Bhatia, Vijak. Analysing Genre: Language Use in Professional Settings. London: Longman, 1993 .

Chardonnens, László Sándor and Rosanne Hebing. "A Descriptive Analysis of Nijmegen, Universiteitsbibliotheek, HS 194, a Late Medieval English Manuscript at Nijmegen University Library." English Studies 92.1 (2011): 20-38.

Doró, Katalin. "Selling their Research: The Linguistic Realization of Rhetoric Moves in English Thesis Abstracts Written by Hungarian Undergraduates." Romanian Fournal of English Studies 10.1 (2013): 181-91.

Hartley, James. "Improving the Clarity of Journal Abstracts in Psychology: The Case for Structure." Science Communication 24.3 (2003): 366-79.

--. "Current Findings from Research on Structured Abstracts." Fournal of Medical Library Association 92.3 (2004): 368-71.

Hirano, Eliana. "Research Article Introduction in English for Specific Purposes: A Comparison between Brazilian Portuguese and English." English for Specific Purposes 28 (2009): 240-50.

Hyland, Ken. Disciplinary Discourses: Social Interaction in Academic Writing. London: Longman, 2000.

--. Metadiscourse: Exploring Interaction in Writing. New York: Continuum, 2005 .

Lave, Jean and Etienne Wenger. Situated Learning: Legitimate Peripheral Participation. Cambridge: Cambridge University Press, 1990.

Löfrgen, Hans. "Cooper's Pioneer: Breaking the Chain of Representation." Nordic Fournal of English Studies 8.3 (2009): 1-19.

Lon, Chuah Ek et al. "Conveying Communicative Intent: Moves and Metadiscourse in Abstract Writing." International fournal of Applied Linguistics and English Literature 1.7 (2012): 56-65.

Lorés, Rosa. "On RA Abstracts: From Rhetorical Structure to Thematic Organization." English for Specific Purposes 23 (2004): 280-302. 
Martín-Martín, Pedro. The Rhetoric of Abstracts in English and Spanish Scientific Discourse: A Cross-Cultural Genre-Analytic Approach. Bern: Peter Lang, 2005 .

Ozturk, Ismet. "The Textual Organization of Research Article Introduction in Applied Linguistics: Variability within a Single Discipline." English for Specific Purposes 26 (2007): 25-38.

Pho, Phuong Dzung. "Research Article Abstracts in Applied Linguistics and Education Technology: A Study of Linguistic Realizations of Rhetoric Structure and Authorial Stance." Discourse Studies 10.2 (2008): 231-50.

Samraj, Betty. "An Exploration of a Genre Set: Research Article Abstracts and Introduction in Two Disciplines." English for Specific Purposes 24 (2005): $141-56$.

San, Lam Yik and Helen Tan. "A Comparative Study of the Rhetorical Moves in Abstracts of Published Research Articles and Students' Term Papers in the Field of Computer and Communication Systems Engineering." International Journal of Applied Linguistics and English Literature 1.7 (2012): 40-50.

Santos, Mauro Bittercourt Dos. "The Textual Organization of Research Paper Abstracts in Applied Linguistics." Text 16. 4 (1996): 481-99.

Sheldon, Elena. "Rhetorical Differences in RA Introductions Written by English L1 and L2 and Castilian Spanish L1 Writers." Journal of English for Academic Purposes 10 (2011): 238-51. Simon, Ellen and Miriam Taverniers.

---. "Advanced EFL Learners' Beliefs about Language Learning and Teaching: a Comparison between Grammar, Pronunciation, and Vocabulary." English Studies 92.8 (2011): 896-922.

Stotesbury, Hilkka. "Evaluation in Research Article Abstracts in the Narrative and Hard Sciences." Journal of English for Academic Purposes 2 (2003): 32741.

Suntara, Watinee and Siriluck Usaha. "Research Article Abstracts in Two Related Disciplines: Rhetorical Variation between Linguistics and Applied Linguistics." English Language Teaching 6.2 (2013): 84-99.

Swales, John Malcolm. Genre Analysis. Cambridge: Cambridge University Press, 1990.

--- Research Genres: Explorations and Applications. Cambridge: Cambridge University Press, 2004.

Tseng, Fan-ping. "Analysis of Move Structure and Verb Tense of Research Article Abstracts in Applied Linguistics Journals." International Journal of English Linguistics 1.2 (2011): 27-39. 
Youdeowei, Anthony et al., eds. Scientific Writing for Agricultural Research Scientists: A Training Resource Manual. Wageningen: CTA, 2012.

Wenger, Etienne. Communities of Practice. New York: Cambridge University Press, 1998.

Zand-Vakili, Elham and Alireza Fard Kashani. "The Contrastive Move Analysis: An Investigation of Persian and English Research Articles' Abstract and Introduction Parts." Mediterranean Fournal of Social Sciences 3.2 (2012): 129-32. 